\title{
Design and implementation of an indoor solar emulator based low-cost autonomous data logger for PV system monitoring
}

\author{
Oday A. Ahmad, Hussain Sayed, Kanaan A. Jalal, Dhari Y. Mahmood, Waleed H. Habeeb \\ Departement of Electrical Engineering, University of Technology, Baghdad, Iraq
}

\begin{tabular}{ll}
\hline \hline Article Info & ABSTRACT \\
\cline { 2 - 3 } Article history: & $\begin{array}{l}\text { With the growing interest in renewable energy resources, a various number } \\
\text { of studies and development for photovoltaic (PV) systems have investigated } \\
\text { to satisfy global needs in energy. The larger interest in PV resources has } \\
\text { increased request for suitable apparatus with which to test PV systems. This } \\
\text { peceived Dec 6, } 2018 \\
\text { Revised Mar 1, 2019 } \\
\text { Accepted Apr 13,2019 }\end{array}$ \\
$\begin{array}{l}\text { PV panel to facilitate PV system testing under real environment conditions. } \\
\text { A low-cost Arduino Mega256 microcontroller-based data acquisition system } \\
\text { (DAQ) approach has been developed to collect the data in term of voltage, }\end{array}$ \\
power and current based on different levels of light intensity and temperature \\
as well as under partial shading conditions. Hence, the proposed system is \\
not just a solar emulator but it's a complete solar emulator-DAQ system that \\
can emulate the sunlight and monitor the PV parameters and then collect and \\
store the data for further research investigation. The proposed monitoring \\
Photovoltaics \\
system provides real time update of the solar panel characteristics at any time \\
in the year without relying on the weather changes. This data acquisition \\
system will be of superior interest for undergraduate and graduate students as \\
it is both open-source and flexible. The details design of the proposed PV \\
solar emulator and data logger and its implementation are described.
\end{tabular}

Copyright @ 2019 Institute of Advanced Engineering and Science. All rights reserved.

\section{Corresponding Author:}

Oday A Ahmed,

Department of Electrical Engineering,

University of Technology,

University of Technology Post Office, P.O. Box: 35299, Baghdad, Iraq

Email: 30205@uotechnology.edu.iq

\section{INTRODUCTION}

The enormous global energy consumption and the predictable depletion of traditional resources are mainly behind the growing interest in the sustainable and environmentally friendly means of generating electricity such as solar energy. Renewable energy resources, particularly solar PV, are good alternatives. Unfortunately, the cost of photovoltaic modules has not so far been reduced enough to achieve global parity without subsidies. Low efficiency of existing solar power supply systems, without MPPT systems, may require nominal capacity for installation that makes solar PV expensive. Thus, it is always necessary to track the maximum energy from the solar panels to harvest all available energy from the cell. For example, failure to track a maximum global power point (MPP) under partial shading conditions is one of the main causes of large power loss. If one wants to find the MPP from the solar panel source, it should be working at different weather conditions to obtain the required data [1-3]. To test and evaluate these MPPT systems at any time in the year without relying on the weather changes, solar array emulator is, in fact, a necessary so that can replicate the characteristic of the real solar array. The PV emulator is required to emulate the sunlight so that the test circumstance is workable, controllable, and reproducible. The solar emulator can be used to emulate the sun irradiation indoor so that obtain the power-voltage curve of the PV that is required to determine the MPP. This is consequently results in accelerate of prototyping required for the greater integration of photovoltaic technology in the world.

Journal homepage: http://iaescore.com/journals/index.php/IJPEDS 
There are several methodologies for designing solar panel emulators [4-21]. Some emulators are commercially available at significant cost which are designed for power rating higher than may be required. The source output of the solar panels can be emulated in the form of the typical Thevenin source, a source of DC voltage connected in a series with resistance, as shown in Figure 1 [7]. Series resistance is consisting of two equal sections, the first series resistance used to simulate the unexpected environmental change by connecting a switch across it. The P-I characteristics based on this method is demonstrated in Figure 2(a), which is compared with P-I curve of the real PV panel, as shown in Figure 1(b). This type of emulator has many limitations such as that it can be considered a good approximation method to represent the P-I PV curve around MPP only. In addition, the veritable characteristics of a PV panel cannot represent accurately through only changing the series resistance. Moreover, the Thevenin source emulator is unable to detect the occurrence of partial shading.

In [3], a constant current power source with I-V characteristics similar to a PV panel has been used to emulate the PV source, as shown in Figure 3. However, this emulator causing a multiple local maximum in PV properties and it would be tricky to emulate partial shading conditions.

In [11-15], the PV emulator was used by irradiating the physical PV panel using a solar emulator. The solar emulator is a device composed of a set of electric light bulbs arranged so that the level of radiation is distributed on the PV panel uniformly. If this emulator has been designed so that the PV panels are placed within the dimensional capacity of the irradiance of the solar emulator, different tests can be carried out [6]. This type of solar emulator will shows an actual dynamics behavior of the PV system because of its real internal capacitance. Therefore, realistic test results can be obtained. On the other hand, monitoring systems are required for recording of a large number of PV parameters such as temperature, radiation, voltages, currents, etc. These systems commonly known as data loggers. However, the devices used to collect data are expensive and require various hardware and software components. In addition, typical data recorders do not match the type of sensors that should be measured well for accuracy and insufficient input channels to deliver specific sensors, such as in the case of thermal sensors or digital sensors.

These problems and constraints, in terms of cost and technological capabilities, prompted us to design and develop a solar emulator with data acquisition system (DAQ) at low-cost and with a flexible design. The main objective of the developed system is to 1) facilitate the research work related to MPPT techniques in indoor environment, 2) capable of emulate the real IV characteristics of PV in addition to 3) monitoring PV parameters using low-cost Arduino microcontroller that based low-cost sensors to monitor the important PV parameters.

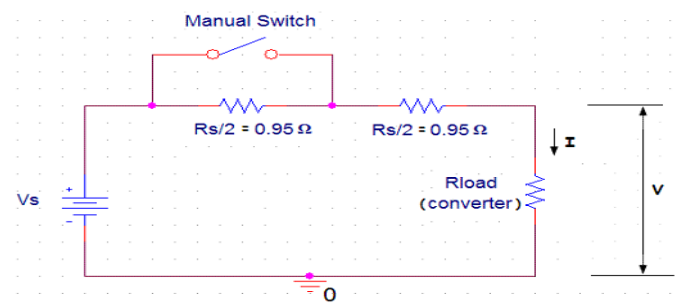

Figure 1. Simple PV source emulator

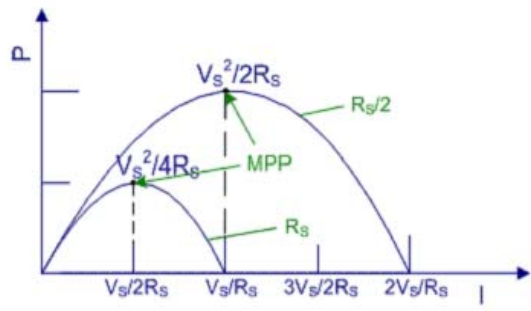

(a)

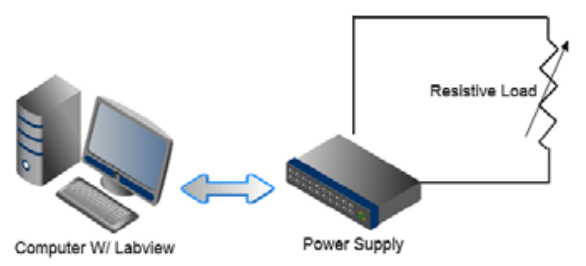

Figure 3. PV Emulator Hardware Setup based DC power supply [3]

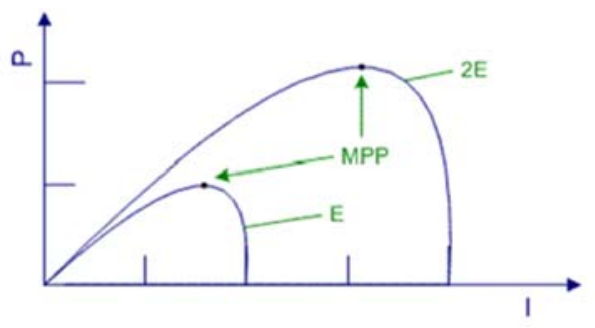

(b)

Figure 2. Power-Current characteristics [2], (a) Thevenin Sourc, (b) Real PV source 


\section{DESIGN REQUIREMENTS OF SOLAR EMULATOR}

The design of the proposed indoor emulator system has been based on a number of the requirements that are considered in this section:

a. The emulator must have the equivalent or comparable range as that of the sun, in any event over the scope of interest where top affectability of PV cells is accomplished.

b. For STC condition, the solar emulator should have an output ability of irradiance level up to $1000 \mathrm{~W} / \mathrm{m}^{2}$.

c. Have a test plane zone sufficiently large to suit no less than one PV board. Have uniform dissemination of light over the entire territory of the PV board. In the event that the light isn't consistently distributed, it is comparable to an incomplete shading condition, which will cause bending of the I-V qualities and may result in unintended different nearby maxima.

d. Keep up a temperature inside a specific range. It is preferred to keep up the PV cell temperature at STC

e. Be capable of emulating partial shading conditions.

f. Be affordable. The expense to build a solar emulator custom fitted to analysts' unique needs must be inside the (restricted) spending plan of the researcher.

g. Develop a low-cost way to measure the illumination intensity at different irradiance levels.

\section{ASSEMBLED PROPOSED PROTOTYPE OF A SOLAR EMULATOR-DAQ SYSTEM}

The proposed low-cost portable solar emulator-DAQ system is presented in this section. Figure 4 shows the block diagram of the developed solar emulator-DAQ system. The design of this system based on the requirements listed in section 2. The embedded processor board manages other boards, voltage sensors, temperature sensors, light sensors, current sensors and PC connectivity through the use of multiple data protocols based MathWorks Simulink. The interface connection between simulation model and embedded processor that used to capture the data and then read and store them is illustrated in Figure 4 (Bottom Block).

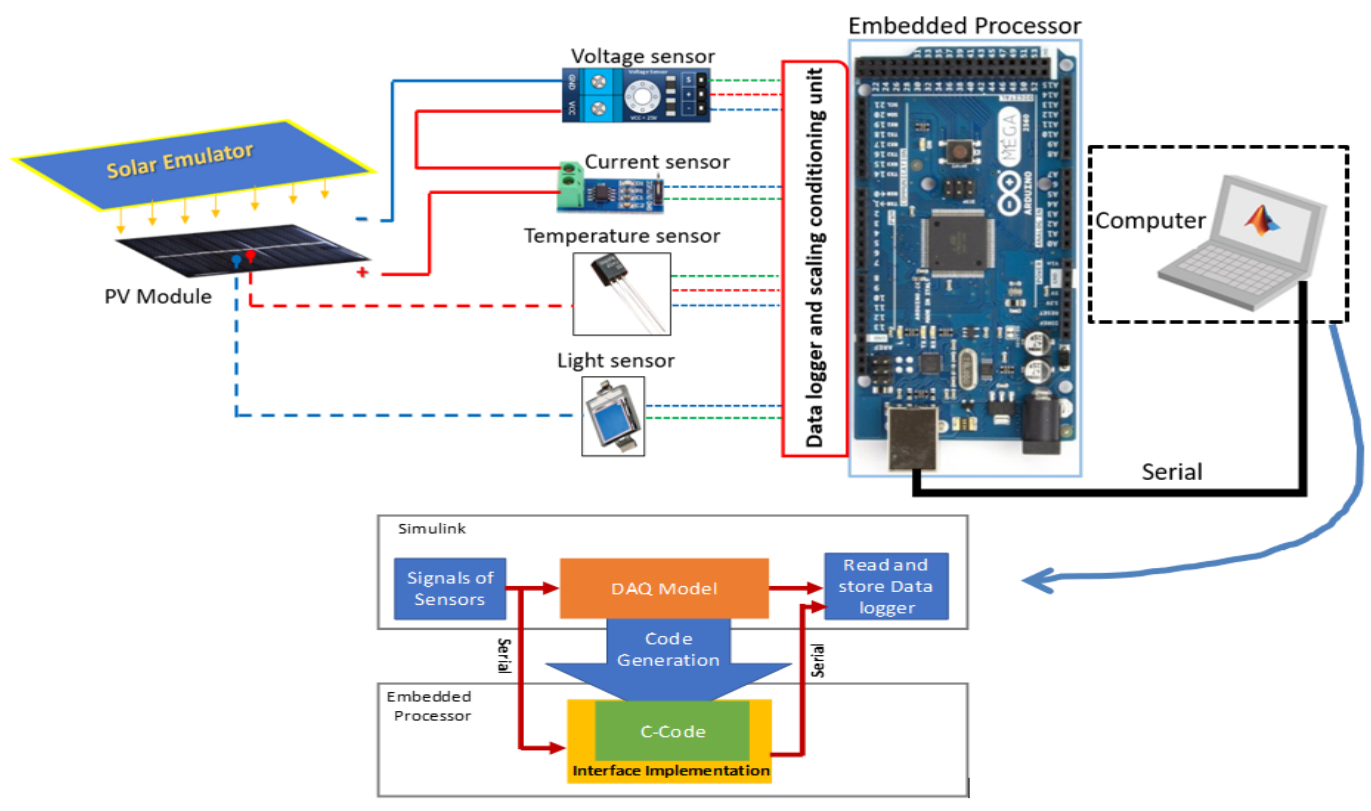

Figure 4. Block diagram of the developed solar emulator-DAQ system

\subsection{Selecting the lamp type}

Sunlight spectrum changes with time and area. Its covers a wide spectrum range from bright $(\sim 10 \mathrm{~nm})$ to the far infra-red $(\sim 1,000 \mu \mathrm{m})$. To permit assessment and comparison of the performance of various photovoltaic gadgets, standard spectra have been created, as appeared in Figure 5 [15]. Contrasted with power LEDs, halogen lights are less effective however a lot less expensive and offer at present more selections in models, wattage and optical attributes. Considering the affectability scope of PV cells, halogen lights can be a decent option in contrast to sunlight as a light source to enlighten PV modules. Subsequent to

Design and implementation of an indoor solar emulator based low-cost autonomous... (Oday A. Ahmad) 
looking at iridescent power, productivity and cost of different lights, $400 \mathrm{~W}$ halogen lights were picked for further examination as appeared in Figure 6.

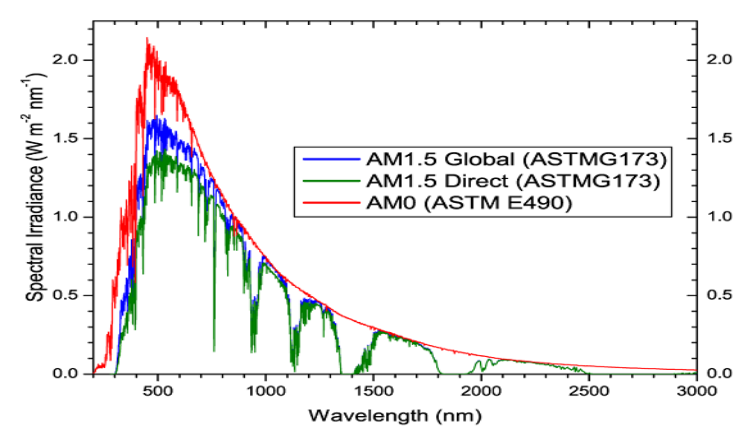

Figure 5. Standard solar spectra [6]

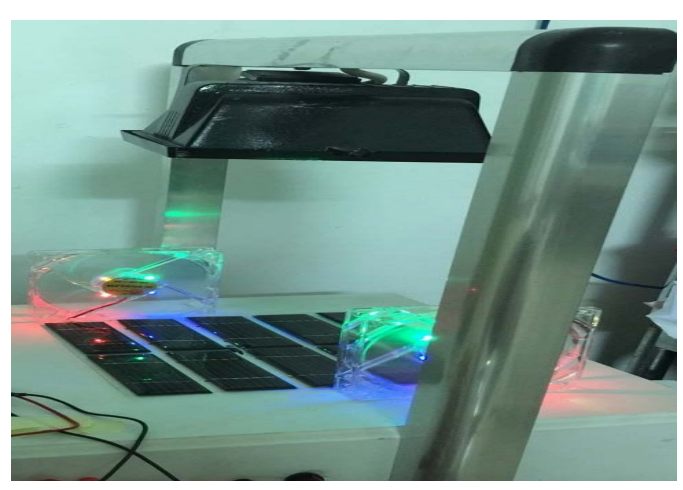

Figure 6. Halogen lamp with stand

\subsection{Selecting the solar panel}

As shown in Figure 7, 10 Polycrystalline Silicon solar panels is selected which can be used to connect the solar panels in different connections and for estimating voltage and current as an element of the solar irradiation. The open circuit voltage for each panel is equal to $6 \mathrm{~V}$ while the short circuit current is up to $100 \mathrm{~mA}$. The specifications of the used solar panel are listed in Table 1.

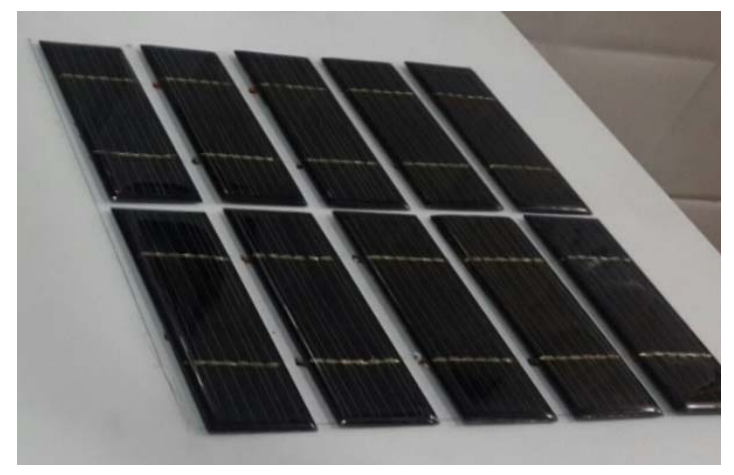

Figure 7. Polycrystalline silicon solar panel

Table 1. Specification of the employed solar panel ((Test condition: $\left.\left.1000 \mathrm{~W} / \mathrm{m}^{2}, 25^{\circ} \mathrm{C}\right)\right)$

\begin{tabular}{cc}
\hline Parameters & Specifications \\
\hline Maximum voltage V & $6 \mathrm{~V}$ \\
Maximum current A & $0.1 \mathrm{~A}$ \\
Open circuit voltage V & $6.9 \mathrm{~V}$ \\
Short circuit current & $0.12 \mathrm{~A}$ \\
Cells diminutions & $119.8 \times 37.8 \mathrm{~mm}$ \\
Maximum Power W & $1 \mathrm{~W}$ \\
\hline
\end{tabular}

\section{a. Mechanical and electrical design}

To acquire the standard state of $1000 \mathrm{~W} / \mathrm{m}^{2}$, the zone lit up by the halogen light should cover all the 10 solar panels without shading. The area of each panel is equal to $119.8 \times 37.8 \mathrm{~mm}$, which means the illumination area should be equal to $10 \times(119.8 \times 37.8) \mathrm{mm}$. Figure 8 illustrated how the illumination should be distributed over the solar panels, where the halogen light is considered a light source point. The distance between the lamp and illuminated area can be given as [14]: 


$$
d=\frac{r}{\tan \left(\frac{\beta}{2}\right)}
$$

where r: radius of the illuminated area, $\beta$ : the angle of the light.

At center of the illuminated area, where $\beta$ equal to $0^{\circ}, 1000 \mathrm{~W} / \mathrm{m}^{2}$ irradiance level can be achieved for d roughly equivalent to $40 \mathrm{~cm}$. A plastic box with dimensions of $(60 \times 40 \times 11)$ in $\mathrm{cm}$ has been selected to design the proposed emulator. All the panel are fixed on the top of the box where aluminum stand is used to fix the halogen lamp as shown in Figure 6.

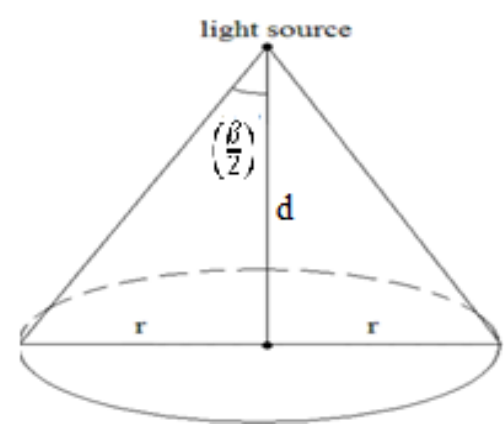

Figure 8. Illustration of illumination

A $220 \mathrm{~V}$ dimmer are used, as shown in Figure 9, so that the light intensity changes in order to simulate in the indoor the impact of the sun oriented illumination in the distinctive hours of the day.

\section{b. Cooling System}

To obtain the PV voltage-current characteristics at standard temperature, a cooling system has been designed using two $12 \mathrm{~V}, 0.22 \mathrm{~A}$ DC Fans, as shown in Figure 10. The required power for them are delivered through $12 \mathrm{~V} 1.5 \mathrm{~A}$ electric charger.

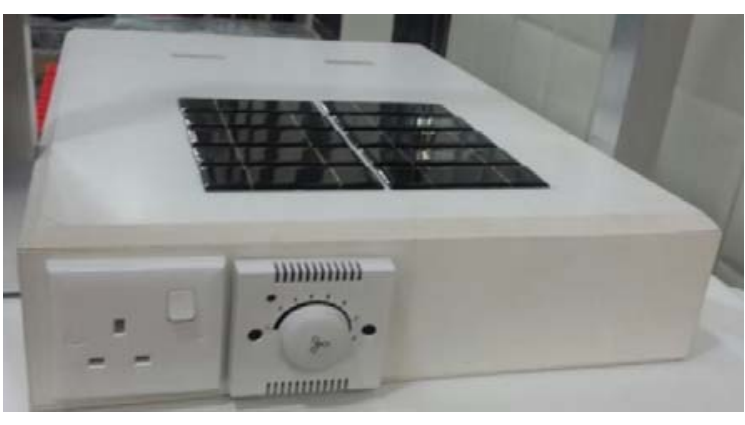

Figure 9. Dimmer light intensity regulator

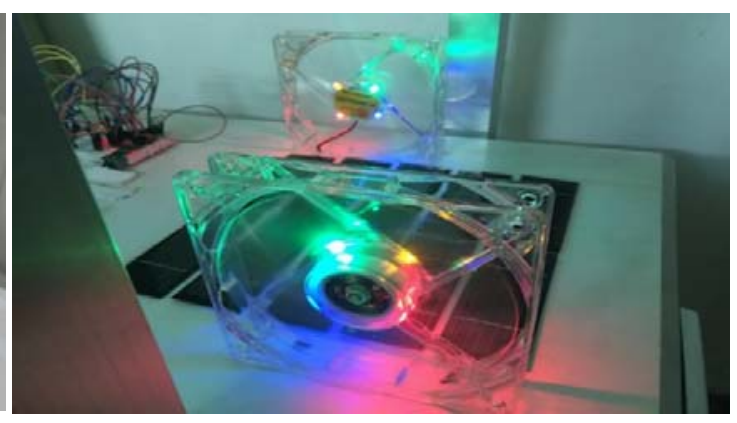

Figure 10. Fan cooling system

\section{DATA ACQUISITION SYSTEM}

Data acquisition systems is the way toward examining signals that measure true physical conditions and changing over the subsequent samples into digital numeric qualities that can be controlled by a PC $[16,17]$. Normally convert analog waveforms into computerized values for processing. The proposed DAQ system composed of the following components:

a. Light sensor:

b. Temperature sensor

c. Current Sensor

d. Voltage sensor

e. Signal conditioning circuitry to convert sensor signals into a form that can be converted to digital values.

Design and implementation of an indoor solar emulator based low-cost autonomous... (Oday A. Ahmad) 
f. Microcontroller to obtain and record the required data from the solar emulator (Arduino Mega has been used to implement the data acquisition monitoring system to obtain and record the required data from the solar emulator.).

g. Software programs to be used as data loggers (Matlab/Simulink has been developed to collect and record the required data in the data logger system).

Table 2 listed the specification of the used sensors in the developed emulator. Figure 11 shows the whole indoor simulator with DAQ hardware set-up.

Table 2. Specification of the employed sensors

\begin{tabular}{cl}
\hline Sensor Type & \multicolumn{1}{c}{ Specifications } \\
\hline BP 104S Silicon PIN Photodiode: & - Dimensions (in mm): $5.4 \times 4.3 \times 3.2$ \\
High speed detector for infrared & - Radiant sensitive area (in mm2): 7.5 \\
radiation & - Daylight blocking filter matched with $940 \mathrm{~nm}$ emitters \\
& - Angle of half sensitivity: $\phi= \pm 65^{\circ}$ \\
& - Reverse voltage: $60 \mathrm{~V}$ \\
LM35 Precision Centigrade & - Operates From $4 \mathrm{~V}$ to $30 \mathrm{~V}$ \\
Temperature Sensors & - Less Than $60-\mu \mathrm{A}$ Current Drain \\
& - Low Self-Heating, $0.08^{\circ} \mathrm{C}$ in Still Air \\
& - Rated for Full $-55^{\circ} \mathrm{C}$ to $150^{\circ} \mathrm{C}$ Range \\
ACS712 Hall Effect Current Sensor & -66 to $185 \mathrm{mV} / \mathrm{A}$ output sensitivity \\
& $-2.1 \mathrm{~K} \mathrm{Vrms} \mathrm{minimum} \mathrm{isolation} \mathrm{voltage}$ \\
& - Total output error $1.5 \%$ at TA $=25^{\circ} \mathrm{C}$ \\
\hline
\end{tabular}

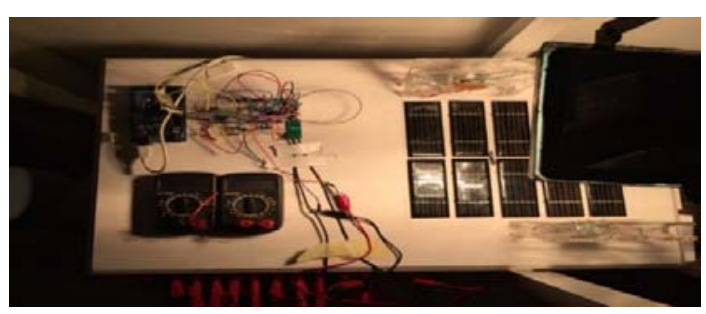

Figure 11. Indoor simulator with DAQ hardware set-up

\subsection{Light and temperature sensors}

To measure the light intensity, BP $104 \mathrm{~S}$ photodiode is used as light sensor. This device is a photodiode which has a spectral sensitivity range of 400-1100nm. Its light-sensitive area is exceptionally little $(2.2 \mathrm{~mm}$ by $2.2 \mathrm{~mm})$ and the thickness is just $1.2 \mathrm{~mm}$. This light sensor has a very low current, thus it should be amplified through separate amplifier board for exact light estimations. Figure 12(b) shows the designed amplification circuit, where the resistance $\mathrm{R}_{\mathrm{f}}$ is added to adjust the calibration of the photodiode detector. The ambient air and PV module temperatures are measured using LM35 integrated circuit sensor. This sensor is compatible with the Arduino board with an electrical output proportional to the temperature $\left(\right.$ in ${ }^{\circ} \mathrm{C}$ ). The photodiode and temperature sensor was mounted in the center of the emulator board as shown in Figure 12(a).

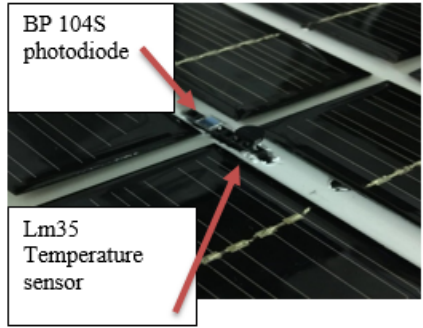

(a)

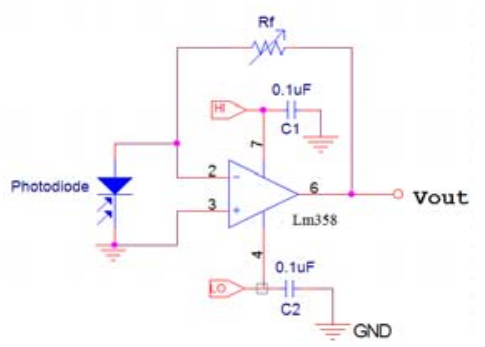

(b)

Figure 12. a) Position of temperature and light sensors, b) Amplification circuit of the photodiode detector 


\subsection{Current and voltage measurement}

The measurements are the most basic part of the DAQ system. It is imperative that the measurements should be possible with a decent precision, so better proficiency can be accomplished toward the end. The analogue input pins from the used microcontroller board accept voltage between 0 to $5 \mathrm{~V}$, hence the sensors output must be scaled to this acceptable limits. To trace the I-V curve of the PV module using the DAQ system the PV current and voltage should be measured. The terminal current is taken using AC712 hall-effect current sensor with a resolution of $0.185 \mathrm{~mA}$ and output error of $1.5 \%$. For PV voltage measurements voltage divider with $R_{1}=20 \mathrm{k}$ ohm and $R_{2}=10 \mathrm{k}$ ohm are used. A 4.7V Zener diode are added to protect the ADC of the microcontroller. Figure 13 shows the Arduino microcontroller connected with signal conditioning units.

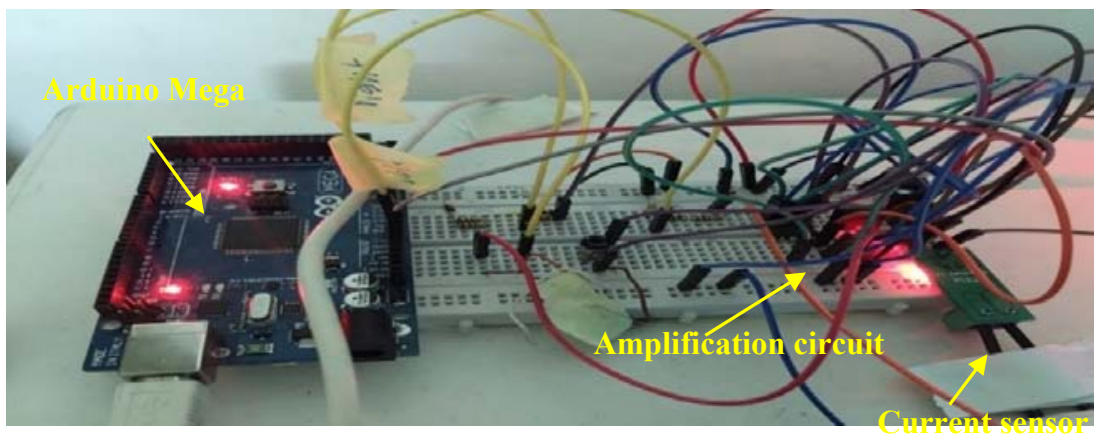

Figure 13. Arduino with signal conditioning units

\subsection{Data logger}

The required data to obtain the V-I and P-I curve of the PV system under different irradiance and temperature levels are acquired using Arduino Mega 2650 based on automatic code generation facilities provided by the MathWorks Simulink. Figure 14 shows the developed DAQ system based on Arduino Matlab-Simulink support package. The voltage, current, temperature and light intensity are acquired and then rescaled to obtain the real data of the PV solar emulator.

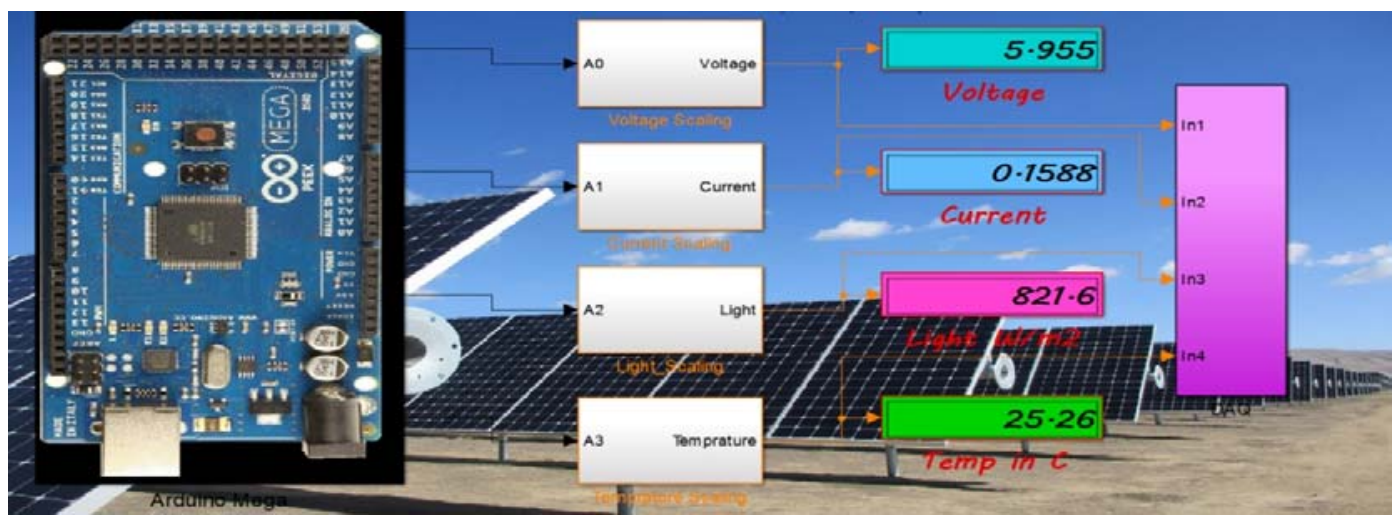

Figure14. Arduino Matlab-Simulink DAQ system

\section{OFF-LINE AND ON-LINE PV CHARACTERISTICS}

Different tests have been done to plot the V-I characteristics of the solar cell. The test was to find the characteristics of the single and multi-parallel solar cell connections. Figure 15(a) show the V-I and P-V characteristics of single solar cell for two different light intensities (at $200 \mathrm{w} / \mathrm{m}^{2}$ and $800 \mathrm{w} / \mathrm{m}^{2}$ see Figure 16(a)), while Figure 15(b) show the V-I and P-V characteristics of 10 solar cells connected in parallel for two different light intensities for roughly constant temperature level which is monitored using DAQ

Design and implementation of an indoor solar emulator based low-cost autonomous... (Oday A. Ahmad) 
system as shown in Figure 16(b). The V-I data of PV panel monitored by the Arduino data logger for different load changes and at different irradiance are shown in Figures 17 and 18 respectively.
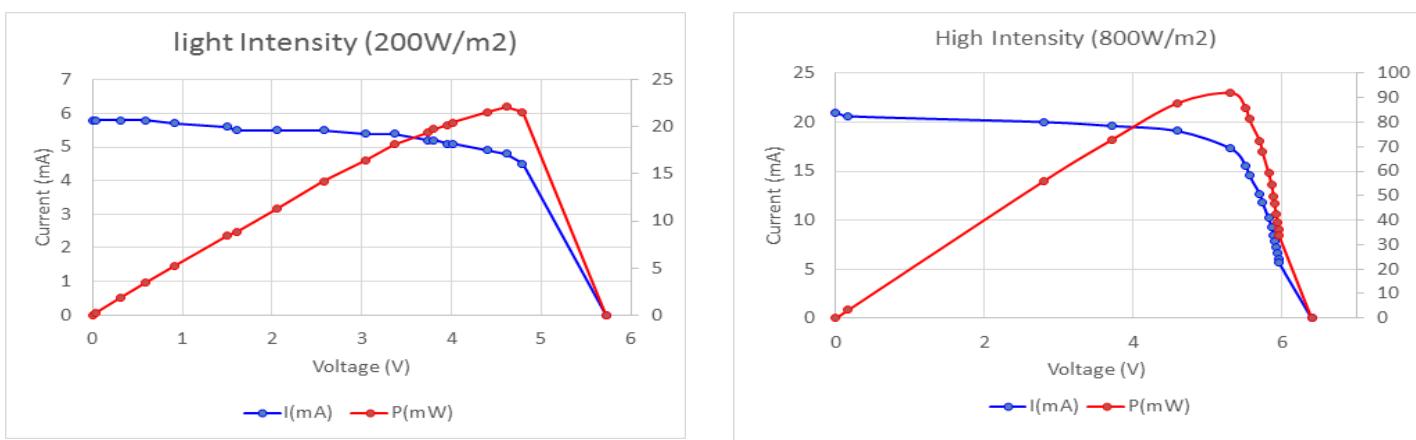

(a)
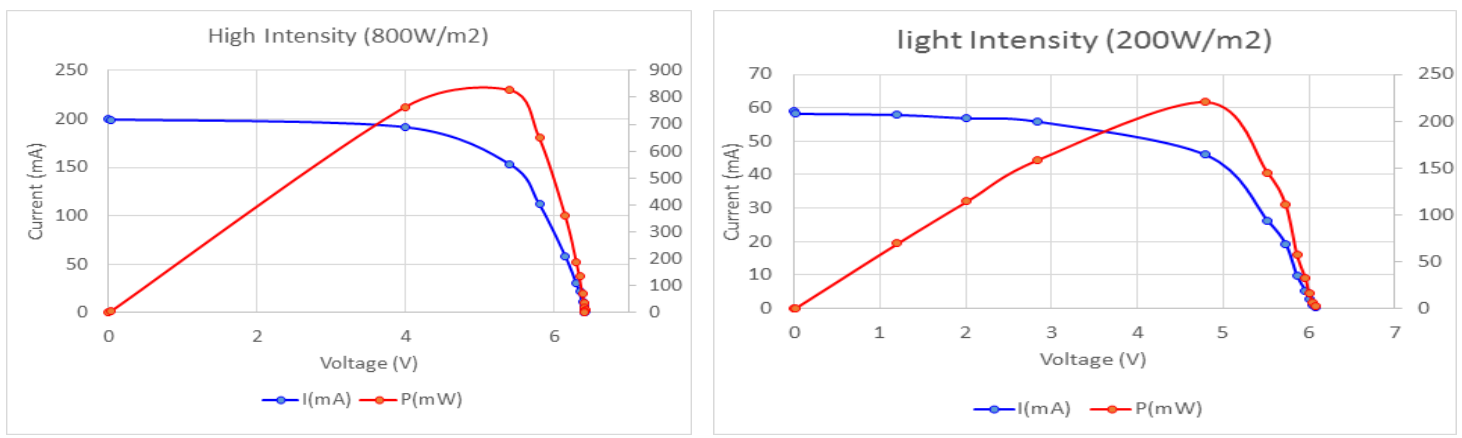

(b)

Figure 15. a) I-V and b) P-V characteristics of single and multi-solar cells connections for different solar irradiance intensity

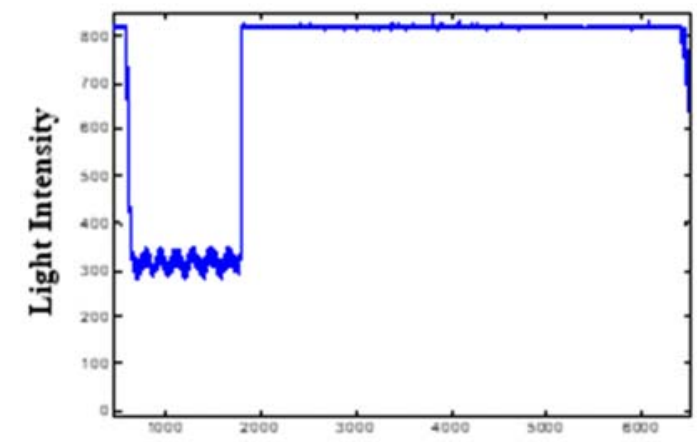

(a)

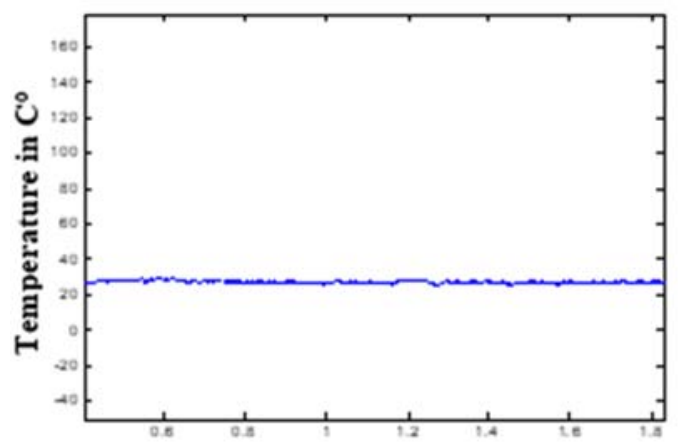

(b)

Figure 16. Acquired data using proposed DAQ system, (a) Irradiance data, (b) Temperature 


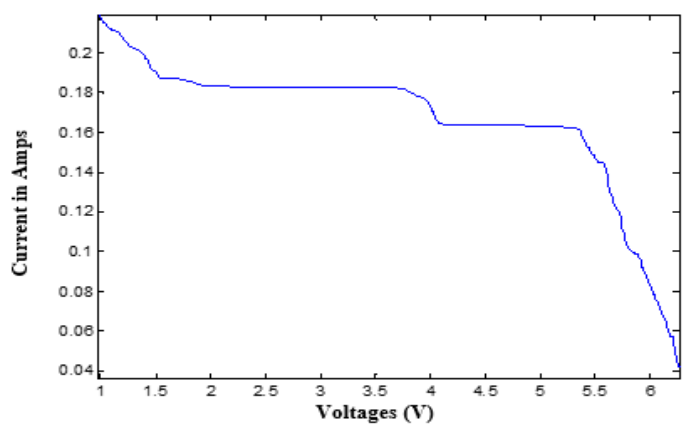

Figure 17. I-V characteristics of solar cells parallel connections measured by proposed DAQ system

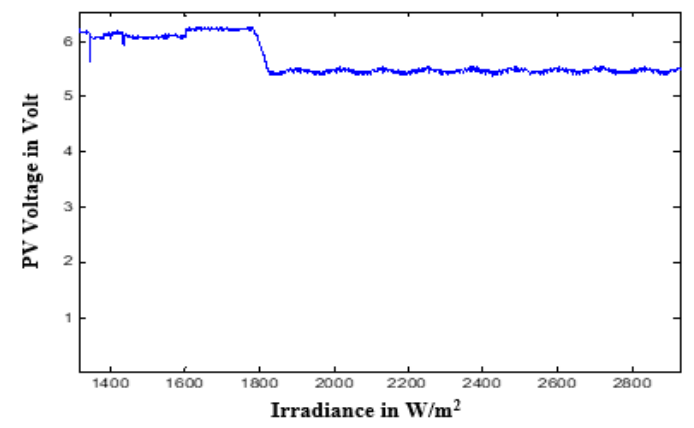

Figure 18. PV voltages measured by proposed DAQ at different light intensity

\section{CONCLUSIONS}

A controllable consistent state solar emulator has been planned and built utilizing of an halojen light together with a low-cost portable data logger based on an open-source microcontroller programmed based on Arduino Matlab interface package. The halogen light has been installed with the goal that uniform dispersion of brightening to the PV panel(s) can be accomplished. The light intensity can be changed through using a dimmer regulator. This prototype emulator is an exceptionally valuable facility for the trials to get the actual PV attributes at various conditions and can also be used to facilitate the research work in the field of MPPT techniques. To enhance and monitor the performance of a PV system, data acquisition systems has been designed and implemented. The collected data that obtained by monitoring the PV parameters, such as voltage, current, temperatures and irradiances are fed to the computer via the Arduino Mega256 and acquired using a Matlab environment for analysis. The control interface has been developed by utilizing ArduinoMatlab Target Package software.

\section{REFERENCES}

[1] J. A. Gow, and J. A. M. Bleijs, "A modular DC-DC converter and maximum power tracking controller for medium to large scale photovoltaic generating plant," Proceedings of the 8th European Conference on Power Electronics and Applications. EPE'99, 1999.

[2] San Luis Obispo, "Photovoltaic emulator adaptable to irradiance, temperature and panel-specific i-v curves," MSC thesis, California Polytechnic State University, 2011.

[3] Dolan, D.S.L., Durago, J. and Taufik, "Development of a photovoltaic panel emulator using labview" in 37th IEEE Photovoltaic Specialists Conference (PVSC), 19th-24th June, pp. 1795-800, Seattle, WA, USA, 2011.

[4] N Erraissi, M Raoufi, Noura Aarich, M Akhsassi, A Bennouna, "Implementation of a low-cost data acquisition system for "PROPRE.MA" project," Measurement, Vol 117, pp 21-40, 2018.

[5] N. N. Mahzan, A. M. Omar, L.Rimon, S. Z. Mohammad Noor, M. Z. Rosselan "Design and Development of an Arduino Based Data Logger for Photovoltaic Monitoring System," International Journal of Simulation Systems, Science \& Technology, Vol. 17, No. 41, 2016.

[6] Ristaldi L, Faifer M, Leone G, Vergura S., "Reference strings for statistical monitoring of the energy performance of photovoltaic fields," in International Conference on Clean Electrical Power (ICCEP), 2015.

[7] Kawamura H Mishina T, Yamanaka S, Kawamura H, Ohno H. and K.Naito, "A studyof the automatic analysis for the I-V curves of a photovoltaic subarray," in Proceedings of the 29th IEEE Photovoltaic Specialists Conference, 2008.

[8] Wandhare, R.G. and Agarwal, V., "A low cost, light weight and accurate photovoltaic emulator," in 37th IEEE Photovoltaic Specialists Conference (PVSC), 19th-24th June, pp. 1887-92, Seattle, WA, USA, 2011.

[9] N. Veissid, D. Bonnet, and H. Richter, "Experimental investigation of the double exponential model of a solar cell under illuminated conditions: considering the instrumental uncertainties in the current, voltage and temperature values," Solid-State Electronics, Vol. 38, No. 11, pp. 1937-1943, Nov. 1995.

[10] C. Honsberg and S. Bowden, Photovoltaics, Beta of the 2nd Edition.

[11] Cristaldi L, Faifer M, Lazzaroni M. "A cooperative monitoring and diagnostic architecture for PV systems," in IEEE Sensors Applications Symposium (SAS), 2016.

[12] J. E. Kaufman and J. F. Christensen, "IES Lighting Handbook, Illuminating Engineering Society of North America," 5th edition 1972.

[13] Valentin Dogaru Ulieru, Costin Cepisca, "Renewable Energy-Trends and Applications: Data Acquisition in Photovoltaic Systems," INTECHOPEN Book, ISBN: 978-953-307-9, 2011.

[14] E Rezk, I Tyukhov, M Al-Dhaifallah, A Tikhonov, "Performance of data acquisition system for monitoring PV system parameters" Measurement, Vol. 104(2017), pp 204-211, 2017.

Design and implementation of an indoor solar emulator based low-cost autonomous... (Oday A. Ahmad) 
[15] E. Koutroulis, K. Kalaitzakis, "Development of an integrated data-acquisition system for renewable energy sources systems monitoring," Renew. Energy, 28(2003), pp. 139-152, 2003.

[16] Bayark G, CEBECI M. "Monitoring A Grid Connected PV Power Generation System with LabVIEW," in International Conference on Renewable Energy Research and Applications, 2013.

[17] Bensalem S. "Effects of temperature on the characteristic parameters of solar cells" University Ferhat Abbas - Setif Algerie.

[18] Arora JD, Verma AV, Bhatnagar M., "Variation of series resistance with temperature and illumination level in diffused junction poly- and single-crystalline silicon solar cells," J Mater Sci Lett, 5:1210-2, 1986.

[19] Ortiz-Conde A, Lugo-Muñoz D, García-Sánchez FJ., "An explicit multiexponential model as an alternative to traditional solar cell models with series and shunt resistances," IEEE J Photovolt, 2:261-8. 2012.2190265, 2012.

[20] Chouder A, Silvestre S, Sadaoui N, Rahmani L., "Modeling and simulation of a grid connected PV system based on the evaluation of main PV module parameters," Simul Model Pract Theory, 20:46-58.011, 2012.

[21] Gao X, Cui Y, Hu J, Xu G, Wang Z, Qu J, et al. "Parameter extraction of solar cell models using improved shuffled complex evolution algorithm," Energy Convers Manag 157:460-79, 2018. http://dx.doi.org/10.1016/j.enconman.2017.12.033.

\section{BIOGRAPHIES OF AUTHORS}

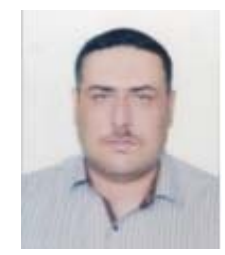

Oday A. Ahmed received his MSc degree in Electrical and Electronic Engineering from University of Technology, Baghdad-Iraq, in 2002. He was awarded a PhD degree from University of Leicester in 2012. Since 2002, he has been a Lecturer in Electrical Engineering in the Department of Engineering at the University of Technology, where he teaches Electrical Machines, Power Systems and power electronics. His field of research covers a wide range of subjects in Renewable Energy Conversion and Energy Storage, from electrical generators and power electronics to power systems and advanced controllers.

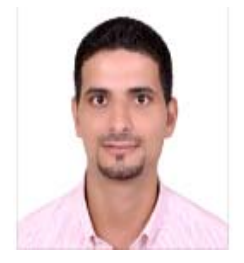

Hussain Sayed has gained his master's degree of science in Systems Engineering from the University of Arkansas at Little Rock - USA, in 2016. His bachelor's of science degree was awarded from the University of Technology - Baghdad -Iraq, in 2010. Mr. Hussain has been working on investigating $\mathrm{SiC}$ power switching devices performance for over four years. He also works on designing high-voltage gain power electronics converters for renewable energy applications. He has published several papers in IEEE proceedings in the U.S. and Canada, in addition to accredited international journal publications. Mr. Sayed has strong theoretical and experimental experiences in using LabVIEW software and equipment in both academia and industrial sectors. Hussain's has also been a review in IEEE and Springers journals.

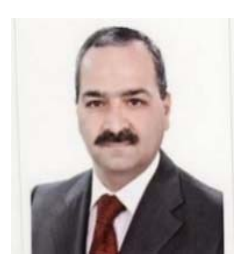

Kanaan A. Jalal is a Lecturer at the Department of Electrical Engineering at the University of Technology, Iraq. He received his Ph.D. in 2007 at University ofTechnology, Iraq. His research interests include electrical power engineering, renewable energy, and the application of soft computing techniques on different power system problems.

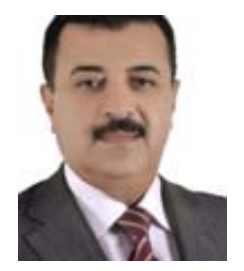

Dhari Y. Mahmood is an asst. Prof at the at the Department of Electrical Engineering at the University of Technology, Iraq. He is currentaly, the dean of the Department of Electrical Engineering. He has gained jis M.Sc and $\mathrm{PhD}$ in Electrical Power Engineering from Sant. Peterburg polytechnical Institute-Russa in 1986 and 1990 respectively. His BSc degree received in 1981 from University of Baghdad-Collage of Engineering -Iraq. Hw wok in the field of renewable energy and power system research. He supervises a large number of graduate students in both master's and Ph.D. degrees.

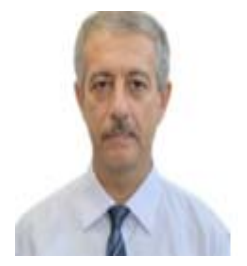

Waleed H. Habeeb is a Lecturer at the Department of Electrical Engineering at the University of Technology, Iraq. He received his M.Sc.. in 1985 at University of Technology, Iraq. His research interests include power electronics, renewable energy, energy efficiency engineering, and cathodic protection systems . 